\title{
I ntra-tumor injection of lentiviral-vector delivered shRNA targeting human papillomavirus E6 and E7 oncogenes reduces tumor growth in a xenograft cervical cancer model in mice
}

\author{
Jiezhong Chen ${ }^{1,2}$, Nigel McMillan ${ }^{3}$, Wenyi Gu ${ }^{2,4}$ \\ 1. Illawarra Health and Mdical Research Institute, University of Wollongong, Wollongong, Australia. 2. Institute of Health \\ and Biomedical Innovation, Queensland University of Technology, Kelvin Grove, Australia. 3. School of Medical Science, \\ Griffith University, Gold Coast, Australia. 4. Australian Institute of Bioengineering \& Nanotechnology, University of \\ Queensland, Brisbane, Australia
}

Correspondence: Jiezhong Chen. Address: Illawarra Health and Mdical Research Institute, University of Wollongong, Wollongong, NSW 2522, Australia. Telephone: 61-242-213-199. Fax: 61-242-218-130. E-mail: jiezhong@uow.edu.au. Wenyi Gu. Address: Australian Institute of Bioengineering \& Nanotechnology, University of Queensland, Brisbane, Australia. Telephone: 61-733-463-814. Fax: 61-733-463-973. E-mail: wgu@uq.edu.au

Received: June 5, 2012

DOI : $10.5430 /$ jst.v2n4p4
Accepted: July 17, $2012 \quad$ Published: August 1, 2012

URL: http://dx.doi.org/10.5430/jst.v2n4p4

\section{Abstract}

Objectives: HPV is known to play a key role in the growth and maintenance of cervical cancer. Its early genes E6 and E7 can activate several intracellular signal pathways for carcinogenesis. Studies have shown that in vitro knockdown of E6 and E7 can reduce the survival ability of cervical cancer cell lines. In this study, we tested the effect of a lentiviral shRNA against E6/E7 on the tumor growth of xenografted cervical cancer HeLa cells.

Methods: In vitro, the growth of HeLa cells transduced with lentiviral shRNA against E6/E7 was compared to controls. In vivo, the $\mathrm{RAG}^{-/}$mice, which are deficient in $\mathrm{T}$ and B lymphocytes were used to establish the HeLa xenografted model. In the treatment group, shRNA against E6/E7 was injected into the tumor directly 30 days after HeLa cell injection when tumors have formed and the injection was repeated at day 60. A lentiviral vector without shRNA was injected in the control group.

Results: HeLa cells transduced with lentiviral shRNA against E6/E7 grew slower than those with transduced with the control vector. The difference in growth rate was significant at day 4 . We also observed that lentiviral shRNA significantly reduced the size of xenografted tumors compared with controls. The average tumor weight is $60 \%$ of the controls.

Conclusions: Our results provide evidence that RNAi may be used for the treatment of cervical cancer by intra-tumor injection.

\section{Key words}

HPV, E6, E7, Cervical cancer, Xenograft tumor, Rag $^{-/-}$mice 


\section{I ntroduction}

Human papillomavirus (HPV) has been identified as a major cause of cervical cancer and is responsible for $99 \%$ cases of the disease ${ }^{[1]}$. Although there are more than 200 types of HPVs, only 12 high risk types cause cancers with HPV16 and HPV18 primarily responsible for cervical cancer ${ }^{[2]}$. Without HPV infection, the risk of cervical cancer is very low. Preventive vaccines against HPV risk types have been demonstrated to be very effective in preventing HPV-caused cervical cancer ${ }^{[3-4]}$. However, these vaccines are not effective as a treatment for the disease. Therefore, there is still an urgent need to find an effective approach to eliminate existing HPVs or HPV oncogenes in cervical cancer cells to treat the disease.

HPV are small non-enveloped double stranded DNA viruses encoding eight genes including the two oncogenes, E6 and E7, which are responsible for carcinogenesis and maintenance of cervical cancer ${ }^{[5,6]}$. It has been demonstrated that the proliferation of human cervical cancer cells is dependent on E6 and E7 gene expression ${ }^{[7,8]}$. These gene sequences can integrate into the host cell genomes and alter multiple intracellular signaling pathways to promote cell proliferation and decrease cell apoptosis ${ }^{[9]}$ which are important for carcinogenesis and cancer progression ${ }^{[10-12]}$. Some signalling pathways altered by E6/E7 have been elucidated (Figure 1) ${ }^{[8,13]}$. E6 inactivates and degrades p53, which can cause cancer cell apoptosis in response to environmental stimulation ${ }^{[14-16]}$. E6 also binds to fas-associated protein with death domain (FADD) and caspase 8 to prevent apoptosis of HPV-infected cells ${ }^{[17]}$. E7 protein targets the pRb tumor suppressor pathway ${ }^{[18]}$. Both E6 and E7 can also activate PI3K/Akt pathway, a well-known survival pathway which plays a key role in many cancers including cervical cancer ${ }^{[19-26]}$. The activation of this pathway is also associated with drug resistance to chemotherapy ${ }^{[27,28]}$. It has been demonstrated that $\mathrm{Rb}$ and PP2A mediate E6/E7 in activating the PI3K/Akt pathway ${ }^{[18,23,29]}$.

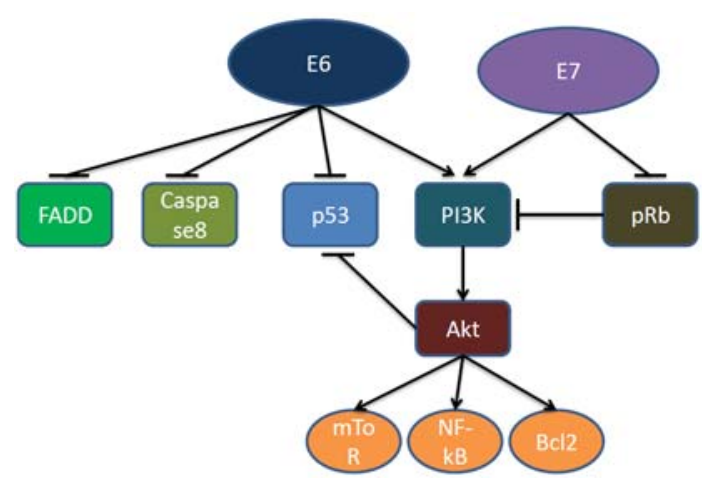

Figure 1. Intracellular Signalling molecules targeted by E6 and E7

Abbreviation: FADD-Fas-associated protein with death domain; PI3K-phosphoinositide 3-kinase; Akt- protein kinase B, pRb, mTOR-mammalian target of rapamycin, NF-kB- nuclear factor-kB; Bcl2-B-cell lymphoma 2.

Inhibition of E6 and E7 has been used as a strategy to stop cervical tumor growth and increase treatment efficacy. At present, the 5 year survival rate after chemotherapy for advanced cervical cancer is 66-79\%, and targeting E6/E7 may further improve therapeutic efficacy ${ }^{[30]}$. A range of small molecule inhibitors to prevent $\mathrm{E} 6$ binding to caspase 8 have been developed ${ }^{[31]}$. RNA interference has also been used to silence gene expression of E6 and this increased the sensitivity of siHa cells to the chemotherapeutic agent cisplatin ${ }^{[32]}$. The disadvantages of siRNA against E6 or E7 are the short half-life of siRNA in cells and also that some cells are not transfected. Lentiviral vectors have been used to deliver short-hairpin RNA (shRNA) which is more stable than siRNA ${ }^{[33-35]}$. We have used a shRNA delivered by a third-generation lentiviral vector to increase the efficacy of inhibition of E6 and E7. It can effectively transduce HeLa cells and cause apoptosis ${ }^{\text {[36] }}$. We have also used shRNA against both E6 and VEGF to increase the treatment effect and this dual shRNA construct has proved to be more effective for the treatment of cervical cancer than single shRNA or combination therapy with chemotherapeutic drugs ${ }^{[36-37]}$. In this study, we used shRNA to target E6/E7 to examine its effect on the proliferation of cervical cancer cells in vitro. In addition, as lentiviral vectors have a strong capacity to transduce both dividing and non-dividing cells we decided to test its therapeutic value in cervical cancer by direct injection into the xenografted 
tumors. These results further support our previous findings, showing that lentiviral shRNA can be a promising approach for cervical cancer treatment, and that this new approach is more applicable to clinical settings.

\section{Materials and methods}

\subsection{Cell culture}

HeLa cells were purchased from ATCC (ATCC, CCL-2) and maintained in complete Dulbecco's Modified Eagles Medium (DMEM, Invitrogen, Australia) with 10\% fetal calf serum and PSG antibiotic mix(100 U/ml penicillin, $100 \mu \mathrm{g} / \mathrm{ml}$ streptomycin, $2 \mathrm{mM} \mathrm{L-glutamine;} \mathrm{Gibco),} \mathrm{at} 37^{\circ} \mathrm{C}$ and $5 \% \mathrm{CO}_{2}$. HeLa cells were then seeded in T75 flasks, 24 or 6 well plates depending on the experiments performed.

\subsection{I nfection of lentiviral shRNA}

The shRNA sequence, expression cassette and lentiviral vector construction was as previously described ${ }^{[36]}$. Briefly, the expression cassette was cloned into the XhoI and Hap I sites of pLentiLox3.7 transfer plasmid and other 3 packaging plasmids pRSVRev, pMDLgpRRE, and pMD.G (contains VSV.G gene) were used for 3rd generation lentiviral vector production.

HeLa cells were transduced in flasks or plates as described ${ }^{[36]}$. Briefly, HeLa cells were trypsinized and counted. Cells were seeded into flasks and plates the day before transduction. Lentiviral-shRNA was diluted in culture medium and one time dose (10 lentiviral particles/cell) was added to the cells ${ }^{[36]}$. After 48 hours the transduced cells were harvested for other assays. The effectiveness of shRNA was assessed by Western blotting as described in our previous study ${ }^{[36]}$.

\subsection{Concentration of lentiviral ShRNA}

Lentiviral shRNA was produced by co-transfection of PLL3.7 containing shRNA against E6/E7 (18E6-1) and packing plasmids to $293 \mathrm{~T}$ cells as previously reported ${ }^{[36]}$. The lentiviral shRNA supernatant was then concentrated by ultracentrifugation at 25,000 rpm for 2 hrs.

\subsection{Xenograft tumor in mice and lentiviral shRNA injection}

Female immuno-deficient $\mathrm{RAG}^{--}$mice were used and $5 \times 10^{5}$ HeLa cells were injected subcutaneously to establish the xeno-tranplant tumors. After the tumors reached a size suitable for shRNA injection at day 30, either lentiviral-shRNA

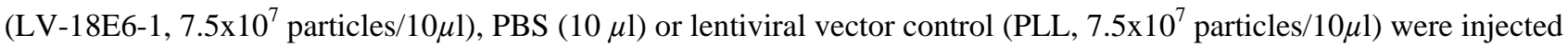
into tumors. The injection was repeated once at day 60 . The mice were sacrificed after 90 days and tumors were isolated and weighed.

\subsection{Data analysis}

The data obtained was expressed as mean \pm SD. An unpaired student t-test was used to analyse the statistical differences and a $P$ value less than 0.05 was regarded as significant.

\section{Results}

\subsection{Effect of shRNA against E6/ E7 on the growth of cervical cancer cell line HeLa I n vitro}

It is known that E6/E7 oncogenes can increase cervical cancer cell growth and decrease apoptosis. Therefore, inhibition of E6/E7 could decrease cell growth and increase apoptosis. We demonstrated shRNA against E6/E7 increased apoptosis in a 
previous study ${ }^{[36]}$. In this study, we aimed to test the effect of shRNA against E6/E7 on cancer cell growth. In order to examine the effect of shRNA E6 on the growth of HeLa cells, 2000 cells of HeLa, HeLa-lentiviral control and HeLa-shRNA against E6/E7 were cultured in 6-well plates. Cell numbers were counted each day for four days. As shown in Figure 2, shRNA against E6/E7 transfected cells grew more slowly than HeLa cells. At day 4 the difference is statistically significant $(p<0.005)$.

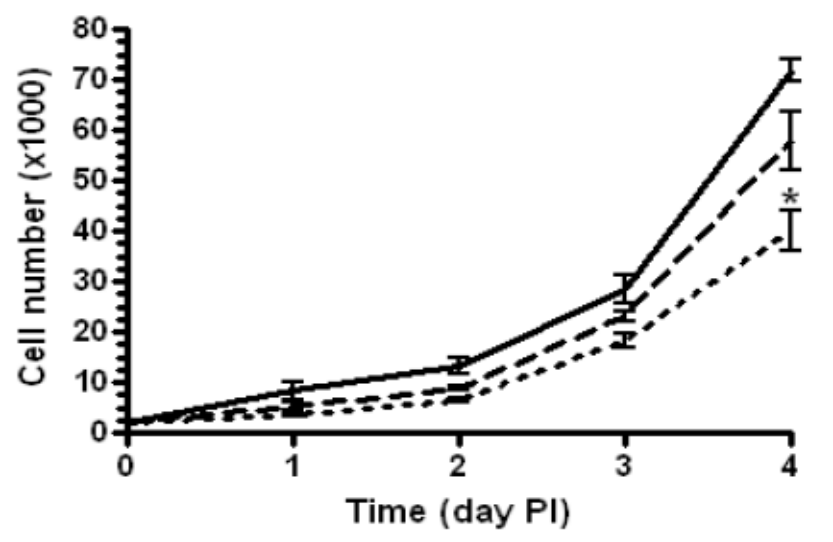

Figure 2. ShRNA E6 inhibited HeLa cell growth in vitro represents control

- - represents PLL shRNA

.... represents shRNA against E6/E7

$\mathrm{N}=5$; * indicates $p<0.05$

\subsection{The effect of shRNA against E6/ E7 in vivo}

After the mice were sacrificed, tumors from each group were isolated and weighed. As shown in Figure 3, the average weight of tumors in the mice in the shRNA E6/E7 injection group is $0.425 \mathrm{~g} \pm 0.076$ and PBS injection group is $0.706 \mathrm{~g} \pm$ 0.096 (Figure 3A). The difference is significant $(p<0.05)$. The size of tumours in mice injected with control lentiviral vector shRNA was not significantly different to those injected with PBS $(0.699 \pm 0.185)$. Sample tumors from shRNA, PBS and PLL injected mice are shown in Figure 3B.

Figure 3. Effect of Intra-tumor injection of shRNA against E6/E7

Panel A showed the tumor weights after injection of shRNA against E6/E7. Panel B showed tumors taken from each group.

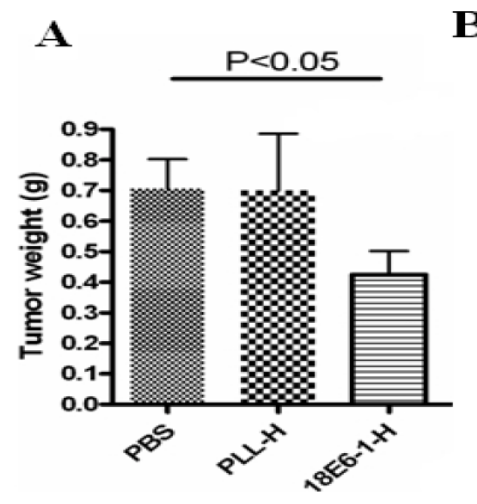

$\mathbf{B}$

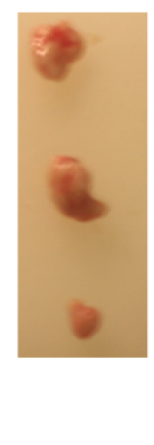

\section{Discussion}

Cervical cancer is the second most common cancer and the third most common cause of cancer deaths in women ${ }^{\text {[38] }}$. Cervical cancer not able to be treated with surgery is treated with radiotherapy and chemotherapy. However, neither are satisfactory treatments and new approaches are needed. Targeting E6/E7 could be an effective new therapy as most cases of cervical cancer are caused by HPV16 and HPV18 and its E6/E7 oncogenes are necessary for cervical cancer initiation and progression ${ }^{[8]}$. These two oncogenes are integrated into the genome of host cells and their constant expression is required for the maintenance of cervical cancer cells. Therefore, it has been proposed that cervical cancer is addicted to E6 and E7 ${ }^{[39]}$. A recent study showed that E6 alone is not sufficient for maintenance of cervical cancer cell growth and 
continuous expression of E7 is also required ${ }^{[40]}$. Therefore, inhibition of E6/E7 and their altered signal pathways is a possible treatment of HPV-caused cervical cancer. Several studies have shown that inhibition of E6 and E7 can reverse change signalling of pRb and p53 by E6/E7 ${ }^{[41-42]}$. In the present study, we demonstrated that shRNA against E6/E7 is able to inhibit the growth of the cervical cancer cell line HeLa cells in vitro.

In an animal model, we demonstrated that intra-tumor injection of shRNA against E6/E7 is effective in retarding the growth of xenograft cervical tumors. Several approaches have been used to deliver shRNA into tumors but efficient delivery is difficult ${ }^{[43]}$. Therefore, we used intra-tumour injection of lentiviral shRNA. Although we only injected in one point which may limit the diffusion of shRNA evenly to the tumor tissue we nevertheless significantly reduced tumour size. It suggests that shRNA could be used alone or combined with other therapeutic approaches as a possible treatment. A recent study has shown that intra-tumor injection of siRNA can also reduce the tumor size of xenografted cervical cancer $^{[31]}$. The advantage of shRNA is that it has a longer half-life, more than two weeks in transfected cells, whilst siRNA's half-life is about 2 days in transfected cells and only a few minutes in vivo circulating system ${ }^{[37,44]}$. In addition, shRNA can also transfect both dividing and non-dividing cells with high efficiency.

Drug resistance to chemotherapy and radiotherapy in cervical cancer is a major issue, leading to treatment failure. It has been demonstrated that E6 and E7 are related to resistance to radiotherapy and inhibition of these two genes can increase treatment efficacy ${ }^{[45]}$. The most common chemotherapeutic agent for cervical cancer is cisplatin which has been used since $1985^{[46]}$. It has been combined with other chemotherapeutic agents recently including paclitaxel, vinorelbine, gemcitabine and topotecan. E6 activated Akt pathway has been associated with cisplatin resistance ${ }^{[26]}$ and it has been shown that treatment with siRNA against HPV18 E6 increased the sensitivity of the cells to some chemotherapeutic agents ${ }^{[42]}$. Radiotherapy in cervical cancer is carried out by pelvic external-beam and intracavitary brachytherapy and remains a common treatment option. E6 and E7 have been shown to increase resistance to radiotherapy ${ }^{[45]}$. Targeted therapy against cervical cancer such as anti-EGFR, anti-angiogenesis and mTOR inhibition has been proposed and shRNA inhibition of E6 and E7 could be combined with these targeted therapies to increase efficacy. Zheng et al showed that ribozyme inhibited E6 and E7, resulted in increased sensitivity to chemotherapeutic agents and radiotherapy ${ }^{[47]}$. SiRNA against E6/E7 has also been shown to have a synergistic effect with cisplatin in causing apoptosis ${ }^{[48]}$. We have also shown that shRNA against E6/E7 has a synergistic effect with cisplatin in HeLa cells and HeLa stem cells ${ }^{[36-37]}$. It will be interesting in future studies to characterise the combinational application of shRNA E6/E7 in an in vivo model of cervical cancer.

In summary, our present study showed that shRNA against E6/E7 can reduce HeLa cell proliferation. It is an addition to our previous study that this shRNA increased apoptosis. We also studied a new approach using intratumor injection to deliver shRNA and demonstrated it can reduce tumor growth in a xenograft model. Further studies are warranted to investigate the effectiveness of shRNA against E6/E7 in combination with other therapies.

\section{References}

[1] Stanley, M., Pathology and epidemiology of HPV infection in females. Gynecol Oncol. 2010; 117(2 Suppl): S5-10. PMid:20304221 http://dx.doi.org/10.1016/j.ygyno.2010.01.024

[2] Schiffman, M., et al., Human papillomavirus testing in the prevention of cervical cancer. J Natl Cancer Inst. 2011 ; $103(5)$ : 368-83. PMid:21282563 http://dx.doi.org/10.1093/jnci/djq562

[3] Frazer, I.H., G.R. Leggatt, and S.R. Mattarollo, Prevention and treatment of papillomavirus-related cancers through immunization. Annu Rev Immunol. 2011; 29: 111-38. PMid:21166538 http://dx.doi.org/10.1146/annurev-immunol-031210-101308

[4] Pinto, L.A., et al., HPV-16 L1 VLP vaccine elicits a broad-spectrum of cytokine responses in whole blood. Vaccine. 2005; 23(27): 3555-64. PMid:15855014 http://dx.doi.org/10.1016/j.vaccine.2005.01.146

[5] Ibeanu, O.A., Molecular pathogenesis of cervical cancer. Cancer Biol Ther. 2011; 11(3): 295-306. http://dx.doi.org/10.4161/cbt.11.3.14686

[6] Zhao, K.N. and J. Chen, Codon usage roles in human papillomavirus. Rev Med Virol. 2011; 21(6): 397-411. PMid:22025363 http://dx.doi.org/10.1002/rmv.707 
[7] Magaldi, T.G., et al., Primary human cervical carcinoma cells require human papillomavirus E6 and E7 expression for ongoing proliferation. Virology. 2012; 422(1): 114-24. PMid:22056390 http://dx.doi.org/10.1016/j.virol.2011.10.012

[8] Moody, C.A. and L.A. Laimins, Human papillomavirus oncoproteins: pathways to transformation. Nat Rev Cancer. 2010; 10(8): 550-60. PMid:20592731 http://dx.doi.org/10.1038/nrc2886

[9] Narisawa-Saito, M., et al., A critical role of MYC for transformation of human cells by HPV16 E6E7 and oncogenic HRAS. Carcinogenesis. 2012; 33(4): 910-7. PMid:22345164 http://dx.doi.org/10.1093/carcin/bgs104

[10] Chen, J. and X.F. Huang, The signal pathways in azoxymethane-induced colon cancer and preventive implications. Cancer Biol Ther. 2009; 8(14): 1313-7. http://dx.doi.org/10.4161/cbt.8.14.8983

[11] Chen, J. and N.A. McMillan, Multiple signal pathways in the leukemogenesis and therapeutic implications. Leuk Res. 2007; 31(12): 1759-60. PMid:17544119 http://dx.doi.org/10.1016/j.leukres.2007.04.006

[12] Chen, J. and N.A. McMillan, Molecular basis of pathogenesis, prognosis and therapy in chronic lymphocytic leukaemia. Cancer Biol Ther. 2008; 7(2): 174-9. http://dx.doi.org/10.4161/cbt.7.2.5262

[13] Yugawa, T. and T. Kiyono, Molecular mechanisms of cervical carcinogenesis by high-risk human papillomaviruses: novel functions of E6 and E7 oncoproteins. Rev Med Virol. 2009; 19(2): 97-113. PMid:19156753 http://dx.doi.org/10.1002/rmv.605

[14] Howie, H.L., R.A. Katzenellenbogen, and D.A. Galloway, Papillomavirus E6 proteins. Virology. 2009; 384(2): 324-34. PMid:19081593 http://dx.doi.org/10.1016/j.virol.2008.11.017

[15] Lagunas-Martinez, A., V. Madrid-Marina, and P. Gariglio, Modulation of apoptosis by early human papillomavirus proteins in cervical cancer. Biochim Biophys Acta. 2010; 1805(1): 6-16. PMid:19374936

[16] Chen, J. and X.F. Huang, Activation of p53 for the treatment of cancer. J Cell Biochem. 2009; 107(4): 567-8. PMid:19415675 http://dx.doi.org/10.1002/jcb.22187

[17] Yuan, C.H., et al., Small molecule inhibitors of the HPV16-E6 interaction with caspase 8. Bioorg Med Chem Lett. 2012; 22(5): 2125-9. http://dx.doi.org/10.1016/j.bmcl.2011.12.145

[18] Menges, C.W., et al., Human papillomavirus type 16 E7 up-regulates AKT activity through the retinoblastoma protein. Cancer Res. 2006; 66(11): 5555-9. PMid:16740689 http://dx.doi.org/10.1158/0008-5472.CAN-06-0499

[19] Huang, X.F. and J. Chen, Obesity and pancreatic cancer: possible role of the PI3K/Akt pathway. Surgery. 2010 ; $147(4): 596$. PMid:20079913 http://dx.doi.org/10.1016/j.surg.2009.11.012

[20] Chen, J., The Src/PI3K/Akt signal pathway may play a key role in decreased drug efficacy in obesity-associated cancer. J Cell Biochem. 2010; 110(2): 279-80. PMid:20432241

[21] Chen, J., Is Src the key to understanding metastasis and developing new treatments for colon cancer? Nat Clin Pract Gastroenterol Hepatol. 2008; 5(6): 306-7. http://dx.doi.org/10.1038/ncpgasthep1141

[22] Chen, J., Multiple signal pathways in obesity-associated cancer. Obes Rev. 2011; 12(12): 1063-70. PMid:22093240 http://dx.doi.org/10.1111/j.1467-789X.2011.00917.x

[23] Charette, S.T. and D.J. McCance, The E7 protein from human papillomavirus type 16 enhances keratinocyte migration in an Akt-dependent manner. Oncogene. 2007; 26(52): 7386-90. PMid:17533372 http://dx.doi.org/10.1038/sj.onc.1210541

[24] Contreras-Paredes, A., et al., E6 variants of human papillomavirus 18 differentially modulate the protein kinase B/phosphatidylinositol 3-kinase (akt/PI3K) signaling pathway. Virology. 2009; 383(1): 78-85. PMid:19007961 http://dx.doi.org/10.1016/j.virol.2008.09.040

[25] Spangle, J.M. and K. Munger, The human papillomavirus type 16 E6 oncoprotein activates mTORC1 signaling and increases protein synthesis. J Virol. 2010; 84(18): 9398-407. PMid:20631133 http://dx.doi.org/10.1128/JVI.00974-10

[26] Wu, H.H., et al., cIAP2 upregulated by E6 oncoprotein via epidermal growth factor receptor/phosphatidylinositol 3-kinase/AKT pathway confers resistance to cisplatin in human papillomavirus 16/18-infected lung cancer. Clin Cancer Res. 2010; 16(21): 5200-10. PMid:20959404 http://dx.doi.org/10.1158/1078-0432.CCR-10-0020

[27] Chen J, Targeted therapy of obesity-associated colon cancer Transl Gastrointest Cancer. 2012; 1(1): 44-57.

[28] Chen, J., et al., Insulin decreases therapeutic efficacy in colon cancer cell line HT29 via the activation of the PI3K/Akt pathway. Curr Drug Discov Technol. 2011; 8(2): 119-25. PMid:21513489 http://dx.doi.org/10.2174/157016311795563820

[29] Pim, D., et al., Activation of the protein kinase B pathway by the HPV-16 E7 oncoprotein occurs through a mechanism involving interaction with PP2A. Oncogene. 2005; 24(53): 7830-8. PMid:16044149 http://dx.doi.org/10.1038/sj.onc.1208935

[30] Tan, S., et al., Anticancer drugs aimed at E6 and E7 activity in HPV-positive cervical cancer. Curr Cancer Drug Targets. 2012; 12(2): 170-84. PMid:22165971 http://dx.doi.org/10.2174/156800912799095135

[31] Zhou, J., et al., Transcriptional gene silencing of HPV16 E6/E7 induces growth inhibition via apoptosis in vitro and in vivo. Gynecol Oncol. 2012; 124(2): 296-302. PMid:22056554 http://dx.doi.org/10.1016/j.ygyno.2011.10.028

[32] Tan, S., et al., Human papilloma virus 16 e6 RNA interference enhances Cisplatin and death receptor-mediated apoptosis in human cervical carcinoma cells. Mol Pharmacol. 2012; 81(5): 701-9. PMid:22328720 http://dx.doi.org/10.1124/mol.111.076539 
[33] Kafri, T., et al., Lentiviral vectors: regulated gene expression. Mol Ther. 2000; 1(6): 516-21. PMid:10933976 http://dx.doi.org/10.1006/mthe.2000.0083

[34] Miyoshi, H., et al., Development of a self-inactivating lentivirus vector. J Virol. 1998; 72(10): 8150-7. PMid:9733856

[35] Logan, A.C., et al., Integrated self-inactivating lentiviral vectors produce full-length genomic transcripts competent for encapsidation and integration. J Virol. 2004; 78(16): 8421-36. PMid:15280451 http://dx.doi.org/10.1128/JVI.78.16.8421-8436.2004

[36] Gu, W., et al., Inhibition of cervical cancer cell growth in vitro and in vivo with lentiviral-vector delivered short hairpin RNA targeting human papillomavirus E6 and E7 oncogenes. Cancer Gene Ther. 2006; 13(11): 1023-32. PMid:16810314 http://dx.doi.org/10.1038/sj.cgt.7700971

[37] Gu, W., et al., Inhibition of cervical cancer cell growth in vitro and in vivo with dual shRNAs. Cancer Gene Ther. 2011; 18(3): 219-27. PMid:21102424 http://dx.doi.org/10.1038/cgt.2010.72

[38] Jemal, A., et al., Global cancer statistics. CA Cancer J Clin. 2011; 61(2): 69-90. PMid:21296855 http://dx.doi.org/10.3322/caac.20107

[39] Goodwin, E.C. and D. DiMaio, Repression of human papillomavirus oncogenes in HeLa cervical carcinoma cells causes the orderly reactivation of dormant tumor suppressor pathways. Proc Natl Acad Sci U S A. 2000; 97(23): 12513-8. PMid:11070078 http://dx.doi.org/10.1073/pnas.97.23.12513

[40] Jabbar, S.F., et al., Cervical Cancers Require the Continuous Expression of the Human Papillomavirus Type 16 E7 Oncoprotein Even in the Presence of the Viral E6 Oncoprotein. Cancer Res. 2012. PMid:22700879 http://dx.doi.org/10.1158/0008-5472.CAN-11-3085

[41] Johung, K., E.C. Goodwin, and D. DiMaio, Human papillomavirus E7 repression in cervical carcinoma cells initiates a transcriptional cascade driven by the retinoblastoma family, resulting in senescence. J Virol. 2007; 81(5): 2102-16. PMid:17182682 http://dx.doi.org/10.1128/JVI.02348-06

[42] Koivusalo, R., et al., Chemotherapy compounds in cervical cancer cells primed by reconstitution of p53 function after short interfering RNA-mediated degradation of human papillomavirus 18 E6 mRNA: opposite effect of siRNA in combination with different drugs. Mol Pharmacol. 2005; 68(2): 372-82. PMid:15908516

[43] Wang, S.L., H.H. Yao, and Z.H. Qin, Strategies for short hairpin RNA delivery in cancer gene therapy. Expert Opin Biol Ther. 2009; 9(11): 1357-68. PMid:19761417 http://dx.doi.org/10.1517/14712590903236843

[44] Wu, S.Y., et al., Development of a novel method for formulating stable siRNA-loaded lipid particles for in vivo use. Pharm Res. 2009; 26(3): 512-22. PMid:19023647 http://dx.doi.org/10.1007/s11095-008-9766-1

[45] Vozenin, M.C., et al., Unravelling the biology of human papillomavirus (HPV) related tumours to enhance their radiosensitivity. Cancer Treat Rev. 2010; 36(8): 629-36. PMid:20417037 http://dx.doi.org/10.1016/j.ctrv.2010.03.010

[46] Duenas-Gonzalez, A., et al., Emerging drugs for cervical cancer. Expert Opin Emerg Drugs. 2012; 17(2): 203-18. PMid:22530838 http://dx.doi.org/10.1517/14728214.2012.683409

[47] Zheng, Y., J. Zhang, and Z. Rao, Ribozyme targeting HPV16 E6E7 transcripts in cervical cancer cells suppresses cell growth and sensitizes cells to chemotherapy and radiotherapy. Cancer Biol Ther. 2004; 3(11): 1129-34; discussion 1135-6. http://dx.doi.org/10.4161/cbt.3.11.1215

[48] Jung, H.S., et al., The synergistic therapeutic effect of cisplatin with Human papillomavirus E6/E7 short interfering RNA on cervical cancer cell lines in vitro and in vivo. Int J Cancer. 2012; 130(8): 1925-36. PMid:21630254 http://dx.doi.org/10.1002/ijc.26197 